\title{
Light and growth in marine phytoplankton: allometric, taxonomic, and environmental variation
}

\author{
Kyle F. Edwards, ${ }^{*}{ }^{1}$ Mridul K. Thomas, ${ }^{2}$ Christopher A. Klausmeier, ${ }^{3}$ Elena Litchman ${ }^{4}$ \\ ${ }^{1}$ Department of Oceanography, University of Hawaii, Honolulu, Hawaii \\ ${ }^{2}$ Department of Aquatic Ecology, Eawag: Swiss Federal Institute of Aquatic Science and Technology, Zurich, Switzerland \\ ${ }^{3}$ Department of Plant Biology, Michigan State University, Kellogg Biological Station, Hickory Corners, Michigan \\ ${ }^{4}$ Department of Zoology, Michigan State University, Kellogg Biological Station, Hickory Corners, Michigan
}

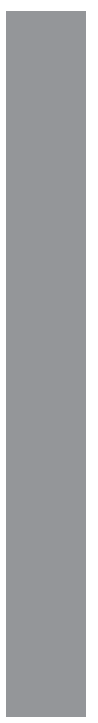

\begin{abstract}
Light-dependent growth of phytoplankton is a fundamental process in marine ecosystems, but we lack a comprehensive view of how light utilization traits vary across genotypes and species, and how this variation is structured by cell size, taxonomy, and environmental gradients. Here, we compile 308 growth-irradiance experiments performed on 119 species of marine phytoplankton from all major functional groups, and characterize growth-irradiance relationships in terms of the initial slope of the growth-irradiance curve $(\alpha)$, the optimal irradiance above which growth declines $\left(I_{\mathrm{opt}}\right)$, and the maximum growth rate $\left(\mu_{\mathrm{max}}\right)$. We find that $\alpha$ declines with increasing cell size, although cell size appears to be a weak constraint on this trait. There are significant differences across taxa in $\alpha$ and $\mu_{\max }$, with dinoflagellates, raphidophytes, and diazotrophs having the lowest values for both traits, and Phaeocystis spp. and diatoms having relatively high values. $I_{\text {opt }}$ does not vary among taxonomic groups, and all traits exhibit large variation within most groups. Open-ocean isolates tend to have higher $\alpha$, lower $I_{\mathrm{opt}}$, and lower $\mu_{\max }$ than coastal isolates, implying adaptation to low light and low productivity. The three traits are correlated across species such that $\alpha$ and $I_{\mathrm{opt}}$ are negatively related while $\mu_{\max }$ is positively correlated with both of these traits. There is some evidence that high $\alpha$ carries a cost of high $\mathrm{N}$ demand even when nitrogen (not light) is limiting. The results elucidate contrasting light-related ecological strategies across phytoplankton and should help improve the parameterization of major functional groups in biogeochemical models.
\end{abstract}

The light environment experienced by phytoplankton can vary enormously, due to attenuation by water, pigments, and other material, variation in insolation and turbulence across seasons and latitudes, and many other factors (Kirk 1994). Likewise, there are large differences among species and genotypes in the traits that characterize light utilization, such as photosynthesis and growth under low vs. high irradiance (Brand and Guillard 1981; Richardson et al. 1983; Moore and Chisholm 1999; Rodriguez et al. 2005), performance under fluctuating light (Litchman 2000; Six et al. 2007), and performance under different irradiance spectra (Wood 1985; Stomp et al. 2004). Trait variation is thought to be explained in part by consistent differences between major taxonomic groups (Richardson et al. 1983; Cullen and MacIntyre 1998; Boyd et al. 2010) as well as cells of different size (Geider et al. 1986; Finkel 2001). For example, diatoms are thought to perform relatively well under both limiting light and excessive light (Richardson et al. 1983) or fluctuat-

*Correspondence: kfe@hawaii.edu ing light (Litchman 1998). Smaller cells are thought to maintain higher photosynthetic rates under light limitation (Geider et al. 1986; Finkel 2001) while larger cells may be less susceptible to photoinhibition under excessive light (Key et al. 2010). Genetic differences in light traits presumably reflect adaptation to distinct light environments, and therefore, differences among species and genotypes should reflect the conditions in which they predominate, such as depth in the water column (Rodriguez et al. 2005) or proximity to land masses (Strzepek and Harrison 2004; Lavaud et al. 2007).

Here, we compile and analyze a comprehensive body of published experiments where phytoplankton growth was measured as a function of irradiance, and where nutrients were not strongly limiting. Growth-irradiance experiments have been performed for a large number of species isolated from diverse environments and representing many taxonomic groups, and therefore, such a compilation can address a number of questions regarding phytoplankton light use. The mechanistic basis for the growth-irradiance relationship 

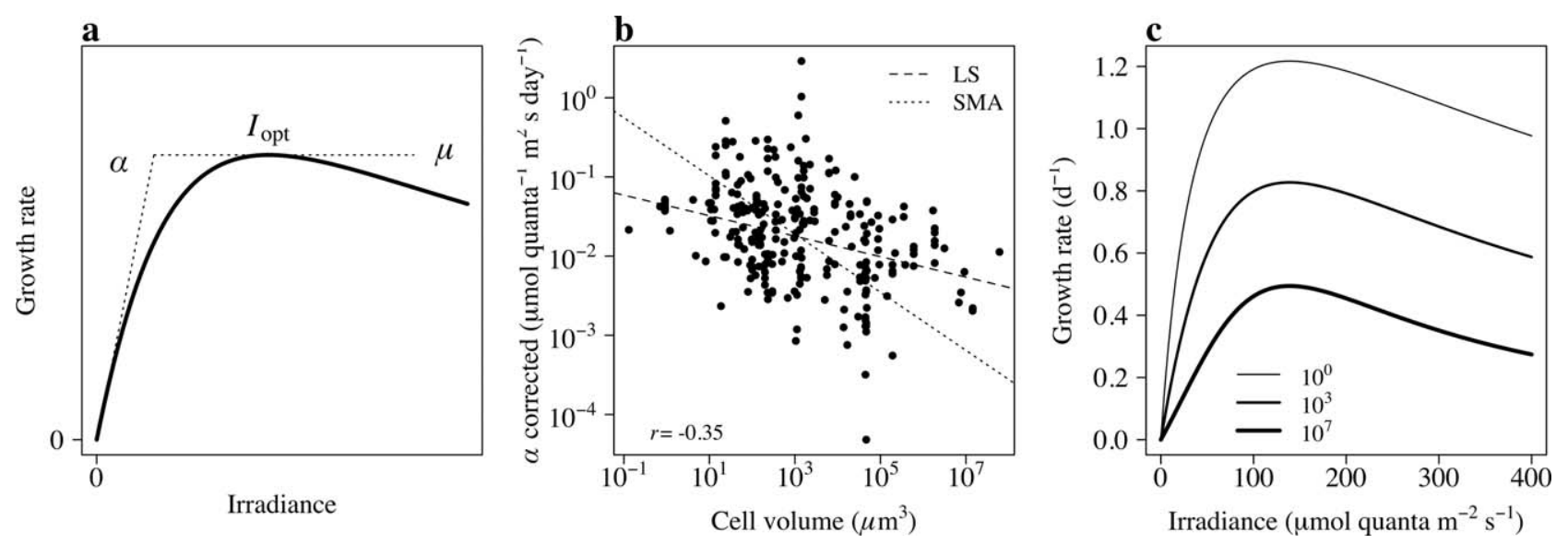

Fig. 1. The growth irradiance curve and allometric relationships. (A) example growth irradiance curve, with labeled parameters: $\alpha$, the initial slope; $I_{\text {opt }}$ the irradiance at which growth rate is maximal; $\mu_{\max }$, the maximum growth rate. (B) $\alpha$ vs. cell volume, showing SMA and LS fits. $\alpha$ has been corrected for daylength and temperature, as described in Methods. (C) Predicted growth irradiance curves for species of different size, $1 \mu \mathrm{m}^{3}, 10^{3} \mu \mathrm{m}^{3}, a^{2}{ }^{2} 0^{7} \mu \mathrm{m}^{3}$. To generate these curves, we analyzed $\mu_{\max }$ using the same methods we used for $\alpha$ and $I_{\text {opt. }}$. These curves show predictions based on LS fits.

has been reviewed elsewhere (Falkowski et al. 1985, Langdon 1988, Talmy et al. 2013). In general, growth increases with irradiance due to an increase in the rate of light-limited photosynthesis, growth saturates at irradiances where photosynthesis is no longer light-limited, and growth may decline at higher irradiances due to photodamage from excess light and/or the costs of photoprotection. Growth-irradiance experiments can be used to characterize three important traits: performance under low light ( $\alpha$, the initial slope of the growth-irradiance curve), the optimal irradiance above which growth is photoinhibited $\left(I_{\text {opt }}\right)$, and the maximum growth rate under optimal irradiance $\left(\mu_{\max } ;\right.$ Fig. $1 \mathrm{~A}$ and Methods; Eilers and Peeters 1988, Schwaderer et al. 2011). These integrated traits reflect the combined effects of many underlying physiological traits, such as the optical absorption cross section of pigments; the cellular investment in components that capture photon energy, fix carbon, synthesize proteins, and protect or repair the photosynthetic machinery under excess light; and the respiratory costs of maintaining these components and synthesizing new biomass (Falkowski et al. 1985, Geider et al. 1998, Talmy et al. 2013). Some of these traits are plastic and acclimate to environmental conditions, but individual genotypes and species are limited in the range of their plasticity (Falkowski et al. 1985, Dubinsky and Stambler 2009), which results in interspecific differences in the integrated growth response to irradiance.

The key traits of the growth-irradiance relationship should determine the outcome of competitive interactions, and thus community structure, under different light conditions (Litchman and Klausmeier 2008). Theory for a wellmixed water column shows that the most important traits for light competition depend on the incident irradiance ( $I_{\mathrm{in}}$, Huisman and Weissing 1994). Under very low $I_{\text {in }}$ populations experience consistently low irradiance, and $\alpha$ should determine the winner in competition. As $I_{\text {in }}$ increases, the population is mixed over depth through a range of irradiance such that growth depends on both $\alpha$ and $\mu_{\max }$, and under high enough $I_{\text {in }}$ a species with higher $\mu_{\max }$ may outcompete one with a higher $\alpha$ (Huisman and Weissing 1994). If $I_{\text {in }}$ is high enough to photoinhibit growth, then a high $I_{\text {opt }}$ may be necessary for persistence, and complex interactions may result where species with high $I_{\text {opt }}$ create enough shade to facilitate the invasion and ultimate dominance of species with lower $I_{\text {opt }}$ (Gerla et al. 2011). Under less turbulent conditions multiple species may partition the water column and coexist with light strategies appropriate to different depths (Stomp et al. 2007, Hickman et al. 2010), and/or strategies reflecting differential abilities under light vs. nutrient limitation (Yoshiyama et al. 2009). Temporal variation in $I_{\text {in }}$ can also maintain a diversity of light-use strategies (Litchman and Klausmeier 2001). Some support for these predictions comes from lab experiments on competition for light (Huisman and Weissing 1999, Passarge et al. 2006), the existence of high vs. low light ecotypes (Moore and Chisholm 1999, Rodriguez et al. 2005), depth-stratified community structure (Furuya and Marumo 1983, Venrick 1999), and seasonal community dynamics predicted by light and nutrient traits (Edwards et al. 2013b).

At this point, we lack a comprehensive understanding of the diversity and distribution of traits related to light use. To ultimately gain a more mechanistic understanding of the structure of phytoplankton communities and how this determines ecosystem processes, it is important to understand whether functional groups based on cell size or taxonomy are strongly correlated with light utilization traits, whether these traits are correlated with each other in ways that reflect tradeoffs or correlated adaptation to the environment, what costs are imposed by high values of particular traits, and how these traits vary across major environmental gradients. 
Here, we examine these questions with a synthesis of published experiments.

\section{Methods}

\section{Literature compilation}

We searched the literature for published measurements of growth rate as a function of irradiance, measured on marine phytoplankton. We collected data from experiments where monotypic cultures were grown without strong nutrient limitation, at least four unique irradiances were used, and the cultures were acclimated to the irradiance treatment before growth was measured. For the current analysis, we excluded isolates from benthic, epiphytic, and ice environments, to focus on pelagic systems. When cell volume was not reported in the original study, when possible we used a measurement of cell volume from a different study in our dataset that used the same species, or from a different study found in the literature.

We aimed to include as much taxonomic and geographic diversity in the analysis as possible, to characterize major patterns in the functional diversity of light utilization traits. Because 71 curves measured growth at only four irradiances, we used a three-parameter curve to quantify the growthirradiance relationship for all experiments in the dataset:

$$
\mu(I) \frac{\mu_{\max } I}{\frac{\mu_{\max }}{\alpha I_{\mathrm{opt}}^{2}} I^{2}+\left(\begin{array}{ll}
1 & \left.2 \frac{\mu_{\max }}{\alpha I_{\mathrm{opt}}}\right)
\end{array}\right) I+\frac{\mu_{\max }}{\alpha}}
$$

where $\mu$ is the specific growth rate $\left(\mathrm{d}^{1}\right)$ as a function of the photon flux density $\left(I, \mu\right.$ mol photons $\left.\mathrm{m}^{2} \mathrm{~s}^{1}\right), \mu_{\max }$ is the maximum growth rate achieved at $I_{\text {opt }}$, the optimal irradiance, and $\alpha$ is the initial slope of the curve (Fig. 1A). This curve was derived by Eilers and Peeters (1988) from a dynamic model of photoinhibition of photosynthesis, and it allows us to compare across species the relative performance under limiting irradiance $(\alpha)$, relative performance under saturating irradiance $\left(\mu_{\max }\right)$, and the irradiance above which photoinhibition reduces growth $\left(I_{\mathrm{opt}}\right)$. Another common equation used to quantify photosynthesis vs. irradiance is that of Platt et al. (1980). Here, we use Eq. (1) because it is explicitly parameterized using the traits we will compare across species. In addition, this curve has a very similar shape to the Platt curve, and we found that the two curves yield very similar trait estimates, and that the curve of Eilers and Peeters generally achieves an equivalent or better fit when quantifed using AICc (Hurvich and Tsai 1989; results not shown).

As irradiance approaches zero, the respiration rate will eventually exceed gross photosynthesis, leading to net negative growth rates. It is possible to represent a constant rate of background "maintenance" respiration by adding a new parameter to Eq. (1). However, for most phytoplankton maintenance respiration is low $\left(\sim 0.02\right.$ day ${ }^{1}$, Geider and Osborne
1989), and in our compilation only 23 experiments measured negative growth at low irradiance. Furthermore, using the modified curve would require us to fit a four-parameter curve to an experiment with four data points in 71 cases, or else drop the experiments with only four irradiances. Therefore, we decided to exclude from the analysis the 23 experiments with negative growth rates, as Eq. (1) is inappropriate for those data. This excluded 17 unique species, including 11 dinoflagellates out of 34 total, although seven of those dinoflagellates were Gambierdiscus spp. from a single study.

Ultimately our dataset included 308 experiments on 119 unique species (see Web Appendix, Table A1, www.aslo.org/ lo/toc/vol xx/issue $\mathrm{x} / \mathrm{xxxa}$.html). The median number of unique irradiances used per experiment was 5 , and the maximum was 37. Data were extracted from figures using Datathief III (www.datathief.org) or from tables where available. Equation (1) was fit to all experiments using maximum likelihood estimation. We tested whether our results were influenced by experiments with small sample sizes, but nearly all results were qualitatively unchanged and quantitatively similar when using only experiments with $>6$ points. The one exception is the analyses of coastal vs. open-ocean isolates; in this case, restricting the dataset excludes too many openocean isolates to make these comparisons.

\section{Statistical analyses}

We used the trait compilation for the following analyses: (1) testing for allometric scaling relationships; (2) testing whether traits differ between taxa and between environments; (3) quantifying correlations between traits; (4) quantifying the relationship between $\alpha$ and chlorophyll content; (5) testing for a relationship between $\alpha$ and the cellular demand for N. Details of the statistical methods are given in subsequent sections.

\section{Quantifying allometric relationships}

We tested for relationships between cell volume and the traits $\alpha$ and $I_{\text {opt }}$. The relationship between $\mu_{\max }$ and cell volume has been analyzed elsewhere using different comparative datasets (Tang 1996, Edwards et al. 2012, Marañon et al. 2013). $\mu_{\max }$ tends to be greater for smaller species (Tang 1996, Edwards et al. 2012), but picophytoplankton have low growth rates, resulting in a unimodal relationship (Marañon et al. 2013). The data have a complex structure, because there are potentially multiple measurements per isolate, multiple isolates per species, multiple species tested per publication, and variation in culture conditions such as temperature and daylength. Therefore, to test for effects of cell size across species, as well as effects of taxonomy and environment (described below), it is appropriate to use mixed models (also known as hierarchical models, Gelman and Hill 2006). We log-transformed $\alpha, I_{\mathrm{opt}}$, and cell volume, for normality of residuals and linearity of relationships. Daylength and temperature were included as continuous predictors to account for variation in culture conditions. Species was included as a 
random effect because some species were measured in multiple experiments, and the publication where the experiments were reported was included as a random effect to account for similarity in trait values due to use of the same experimental methods. For analyses involving $I_{\text {opt }}$, we only used experiments for which the estimated $I_{\text {opt }}$ was less than the maximum irradiance used in the experiment. We took this approach to exclude experiments that did not use high enough irradiances to quantify the onset of inhibition by excess light. We initially fit the models for $\alpha$ and $I_{\text {opt }}$ using generalized additive mixed models (Wood 2012) that allowed for nonlinear effects of log cell volume on these traits, but the model algorithm selected linear relationships as the optimal choice based on an approximate crossvalidation criterion.

The mixed models allowed us to test for effects of volume while appropriately accounting for the complexity of the data. We also wanted to quantify allometric relationships for use in modeling studies. Allometric relationships are often fit using standardized major axis (SMA) regression (Warton et al. 2006). This method fits a line through the middle of the data that does not change if the roles of "predictor" and "response" variables are switched; in contrast, ordinary least squares regression yields a different fitted line if the $y$-axis and $x$-axis are switched (Warton et al. 2006). However, SMA regression has a different limitation, because substantial natural variation in the response variable (e.g., maximum growth rate when regressed against cell volume) will increase the apparent steepness of the allometric slope (Smith 2009). This occurs because the SMA estimator for the slope of $y$ vs. $x$ is the standard deviation of $y$ divided by the standard deviation of $x$ (Smith 2009). Therefore, we present allometric slope estimates both from the mixed model and from SMA regression, as these represent lower and upper bounds on what is feasible given the data.

Because SMA regression does not incorporate covariates such as temperature or random effects for hierarchical structure, we use the fitted mixed models to correct $\alpha$ and $I_{\text {opt }}$ for daylength and temperature (corrected to $20^{\circ} \mathrm{C}$ and 12 -h daylength). For example, if $\alpha$ for species $\mathrm{A}$ was measured at $10^{\circ} \mathrm{C}$, and the fitted model predicts that an increase of 10 degrees will increase $\alpha$ by 0.01 , then 0.01 was added to $\alpha$ to get a temperature-corrected value. We then used the corrected trait values to fit the SMA regressions.

Mixed models were fit with the R package lme4 (Bates et al. 2012), and significance tests were performed with lmerTest (Kuznetsova et al. 2013). Fixed effects were tested using approximate $F$-tests with denominator degrees of freedom calculated with the Satterthwaite approximation. Random effects were tested using likelihood ratio tests (LRT). SMA regression was fit with the package smatr (Warton et al. 2012).

\section{Effects of taxonomy and biogeography}

We wanted to test whether $\alpha, I_{\text {opt }}$, and $\mu_{\max }$ differ between taxonomic or functional groups, and preliminary analyses showed that these effects could be better quantified while simultaneously including information on the geographic origin of the each isolate. We categorized species into the following groups: diatoms, dinoflagellates, coccolithophores, Phaeocystis spp., other miscellaneous haptophytes (Isochrysis, Pavlova, and Prymnesium spp.), miscellaneous small eukaryotes (including prasinophytes, bolidophytes, pelagophytes, and a pinguiophyte), diazotroph cyanobacteria (Trichodesmium, Crocosphaera, and Cyanothece), nondiazotroph cyanobacteria (Prochlorococcus and Synechococcus), and raphidophytes. Although some of these groups have relatively few representatives in the dataset, we used this categorization to help inform ecosystem models and optical classification systems based on similar categories (Hood et al. 2006, Follows et al. 2007, Alvain et al. 2008). Elsewhere in the text, we refer to these groups as taxa for brevity, although it should be noted that not all groups are monophyletic.

We also wanted to test for evidence of trait adaptation to the environments in which different species live. Nearly all experiments reported the location where the cultured strain was isolated from, or reported a culture collection ID that could be used to determine this information. Based on the isolation location, we classified all strains dichotomously as coming from either (estuarine or coastal or shelf) or openocean environments (Fig. 2). We found this classification to be relatively unambiguous based on isolation locations and the fact that most of the estuarine or coastal or shelf strains were isolated from nearshore environments; throughout this article, we will refer to this group as "coastal" for brevity.

We tested for the effect of taxonomic variation and biogeography on the focal traits using mixed models that included environment (coastal vs. oceanic) as a fixed effect, taxon as a random effect, an interaction between environment and taxon as a random effect, daylength and temperature as continuous predictors, and species and publication as random effects.

\section{Trait correlations}

We examined trait correlations across species to see if evidence of tradeoffs or coadapted trait syndromes representing distinct ecological strategies is present. We also performed two analyses to explore how $\alpha$ is related to the biochemical composition of different species. For experiments that quantified the ratio of chlorophyll $a$ to carbon (Chl $a$ : C) under low irradiances, we tested whether $\alpha$ is correlated with Chl $a$ : C. We also explored whether species with high $\alpha$ have a high nitrogen demand even when nitrogen is limiting to growth but light is not. To test this question, we compiled data from other experiments on species in our dataset, where the ratio of nitrogen to carbon content (N : C) was measured under strong nitrogen limitation (see Web Appendix, Table A2). Strong nitrogen limitation could 


\section{Diatoms}

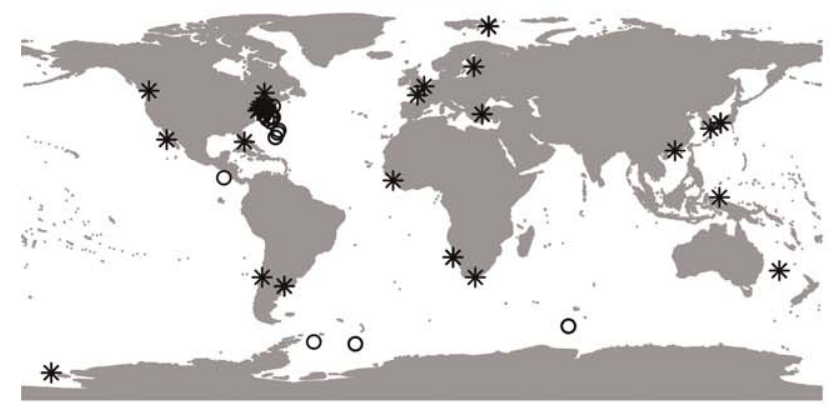

Small Eukaryotes

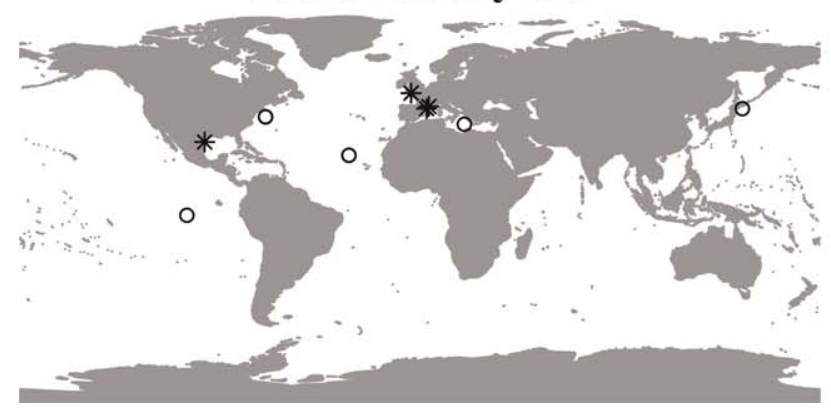

Dinoflagellates

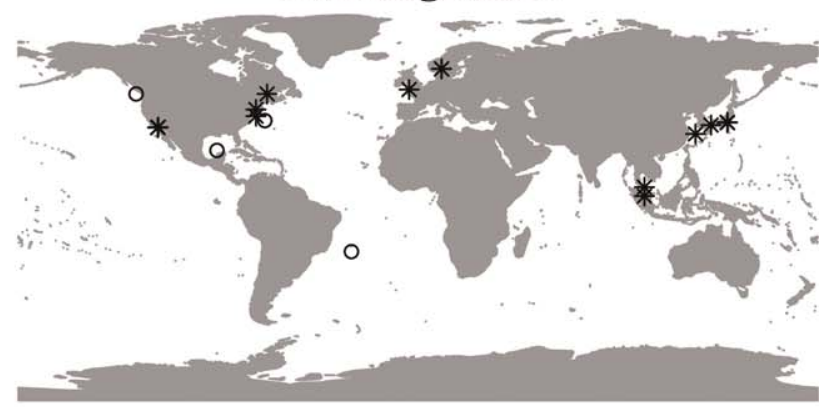

\section{Coccolithophores}

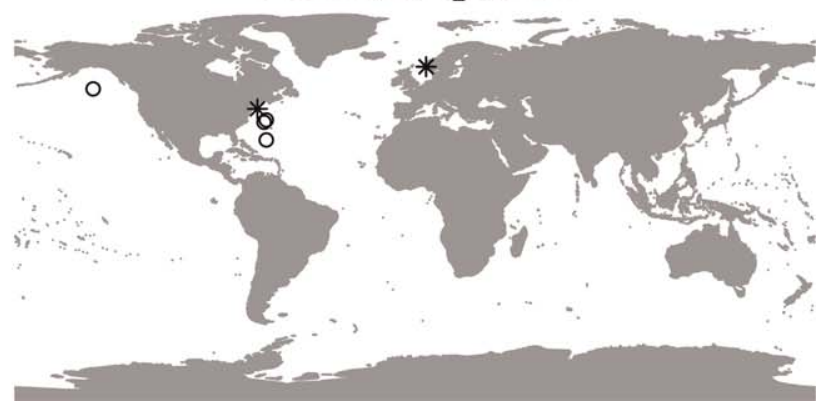

Fig. 2. Locations of isolation for the diatoms, dinoflagellates, small eukaryotes, and coccolithophores for which location information was available. "Coastal" isolates are asterisks and "oceanic" isolates are circles.

be due to growth in a N-limited chemostat at low dilution rate, or stationary phase in $\mathrm{N}$-limited batch culture.

\section{Results}

\section{Allometric relationships}

There is a significant negative relationship between cell volume and $\alpha$ (Table $1 ; p<10^{3}, F_{1,97} 14$ ), although volume explains relatively little variation in this trait (Fig. 1A). For $\alpha$, using only experiments where cell volume was measured did not change the estimated allometric relationship, and so we present analyses using the full dataset here. The SMA and LS slope estimates were substantially different (Table 1, Fig. 1B). In the remainder of the text, we will treat the LS estimate as more accurate, due to the fact that measurement error in cell volume is likely much less than unexplained natural variation in $\alpha$, and unexplained variation in $\alpha$ will cause the slope to appear steeper in SMA regression (Smith 2009; Methods). Based on the LS fit, on average the smallest cells (volume $\sim 1 \mu \mathrm{m}^{3}$ ) and largest cells (volume $\sim 10^{7} \mu \mathrm{m}^{3}$ ) should differ in $\alpha$ by a factor of $\sim 8$ (Fig. 1C). We also found that $\alpha$ tends to increase with the daylength (hours) used in the experiment (slope 0.018, p 0.02, $\left.F_{1,206} 5.5\right)$, as well as the temperature $\left({ }^{\circ} \mathrm{C}\right.$, slope 0.011 , p 0.02, $F_{1,245}$ 5.6). The difference in predicted $\alpha$ between temperature extremes $\left(0^{\circ} \mathrm{C}\right.$ vs. $\left.30^{\circ} \mathrm{C}\right)$ is a factor of $\sim 2.1$. The
Table 1. Coefficients from SMA and least squares (LS) regressions. These regressions quantify the power-law relationships between $\alpha$ and cell volume, and $\alpha$ and Chl- $a$ : C. As described in Methods, for the purpose of these regressions $\alpha$ was corrected for temperature and daylength, and the allometric regression only used experiments where cell volume was measured. Ninety-five percentage confidence intervals are given in parentheses.

\begin{tabular}{lccc}
\hline Model & Fit & Intercept & Slope \\
\hline $\log _{10} \propto$ vs. $\log _{10}$ & SMA & $-0.62(-0.77,-0.47)$ & $-0.37(-0.41,-0.33)$ \\
cell volume & LS & $-1.36(-1.50,-1.22)$ & $-0.13(-0.17,-0.09)$ \\
$\log _{10} \propto$ vs. $\log _{10}$ & SMA & $0.55(-0.35,1.46)$ & $1.56(1.1,2.2)$ \\
Chl $a: C$ & LS & $-0.80(-1.7,0.10)$ & $0.72(0.17,1.26)$ \\
\hline
\end{tabular}

random effect terms quantifying variation between publications, variation between species, and residual variation had respective standard deviations of $0.44,0.05$, and 0.36 ).

In our analysis of $\log _{10} I_{\text {opt }}$ vs. $\log _{10}$ cell volume, we found no significant allometric relationship, even when using only the experiments where cell volume was measured as part of the experiment ( $p \quad 0.065, F_{1,29} \quad 3.7$ ). The trend was toward decreasing $I_{\text {opt }}$ with increasing cell volume (slope 0.021), but due to the weak statistical support we conclude based on our dataset that $I_{\text {opt }}$ does not change with cell size. 

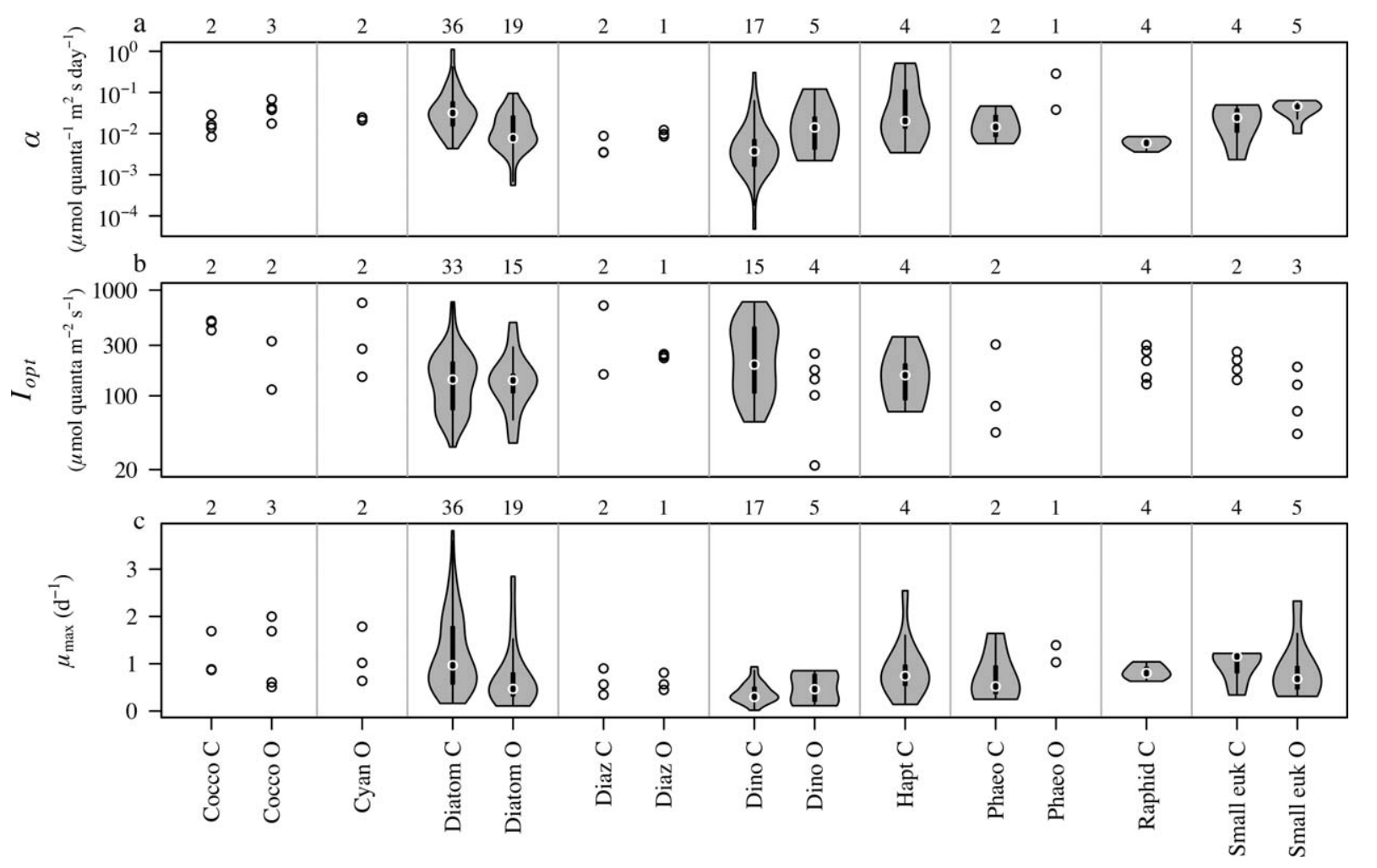

Fig. 3. Trait variation across taxa and environments. (A C) show $\alpha, l_{\mathrm{opt}}$ and $\mu_{\mathrm{max}}$, respectively, with each trait categorized by taxon and environ ment. If $>5$ experiments were available for a taxon environment combination, then a violin plot is shown (i.e., a boxplot overlaid on a vertically ori ented kernel density plot). If five or less experiments were available, the trait value for each experiment is plotted as a separate point. The numbers above the panels show the number of unique species for each group. The taxonomic groups are Cocco coccolithophores, Cyan non diazotroph cyanobacteria, Diatom diatoms, Diaz diazotrophs, Dino dinoflagellates, Hapt misc. haptophytes, Phaeo Phaeocystis spp., Raphid raphidophytes, and Small euk misc. small eukaryotes. After the name of the taxonomic group there is a "C" to denote estuarine, coastal, or shelf isolates, or a "O" to denote oceanic isolates. The same species may have multiple occurrences if multiple experiments were performed, and may be present in both coastal and oceanic categories. Units for the traits are the same as in Figure 1.

\section{Taxonomic and environmental effects}

We tested whether variation in $\alpha, I_{\mathrm{opt}}$, and $\mu_{\max }$ could be explained by taxonomic/functional categories, or by the environment from which the strain was isolated (coastal vs. oceanic). We tested these effects simultaneously to also test for interactions between taxonomy and environment.

For $\alpha$, there is a significant interaction between taxonomy and environment (LRT; $\chi^{2}$ 6.2, $p$ 0.01). This interaction appears to be driven by the fact that $\alpha$ tends to be higher in oceanic isolates for most taxa while for diatoms the opposite is true (Fig. 3). Consistent with this interpretation, when diatoms are removed from the analysis there is no taxonomyenvironment interaction (estimated variance component of zero), a significant effect of environment $\left(F_{1,91} \quad 3.9, p\right.$ 0.05 ), and a significant effect of taxonomy (LRT $\chi^{2} \quad 5.0, p$ $0.03)$. On average the oceanic species have an $\alpha$ that is greater by a factor of $\sim 1.8$. The largest differences between taxa are due to the dinoflagellates, raphidophytes, and diazotrophs having lower $\alpha$ than the other taxa, which have comparable mean values for this trait (Fig. 3). The difference between taxa with the lowest (dinoflagellates) and highest (miscellaneous haptophytes) mean $\alpha$ is roughly a factor of 4 (Fig. 3). When looking at the diatoms alone, there is a significant effect of oceanic species having lower $\alpha\left(\begin{array}{lll}F_{1,77} & 5.3, p & 0.024\end{array}\right)$. Trait differences between environments do not appear to be driven by cell size, because cell size does not differ between environments in our dataset $\left(\begin{array}{lll}F_{1,143} & 0.02, p & 0.9\end{array}\right)$.

For $I_{\mathrm{opt}}$, the variation across isolates is explained only by environment, with oceanic species tending to have lower $I_{\text {opt }}$ than coastal species (Fig. 3). Diatoms run counter to this trend as well (Fig. 3), but the model shows no significant taxonomy-environment interaction (LRT $\chi^{2}$ 3.13, p 0.08). When this interaction is removed from the model, there is a significant effect of environment $\left(F_{1,129} \quad 5.8, p\right.$ 0.02 ), and no significant variation between taxa (estimated variance component of zero). Coastal and oceanic taxa differ on average by a factor of 1.5 , corresponding to a predicted $I_{\text {opt }}$ equal to 175 and 114 , respectively.

For $\mu_{\max }$, there is large variation across taxa (LRT $\chi^{2} \quad 8.9$, $p \quad 0.003)$, and at the same time coastal species tend to 


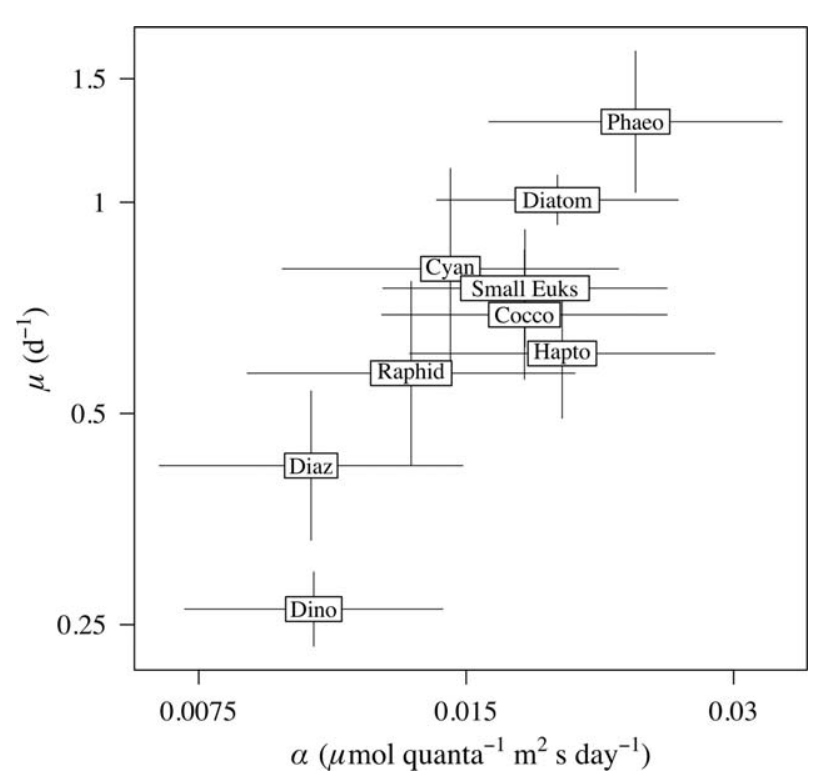

Fig. 4. Correlation between group mean $\mu_{\max }$ and group mean $\alpha$, plot ted on log axes. Group mean estimates are derived from the mixed models that also account for effects of temperature, environment of ori gin, etc. Bars show the standard errors for the group means. Group labels are Cocco coccolithophores, Cyan non diazotroph cyanobac teria, Diatom diatoms, Diaz diazotrophs, Dino dinoflagellates, Hapt misc. haptophytes, Phaeo Phaeocystis spp., Raphid raphido phytes, and Small Euk misc. small eukaryotes. have higher $\mu_{\max }$ than oceanic species $\left(F_{1,161} \quad 3.9, p\right.$ 0.05). There is no interaction between taxonomy and environment (estimated variance component of zero). Phaeocystis spp. and diatoms have the highest $\mu_{\max }$ (respective means of 1.25 day $^{1}$ and 0.98 day ${ }^{1}$, assuming 12 -h daylength and $20^{\circ} \mathrm{C}$ ) while dinoflagellates, diazotrophs, and raphidophytes have the lowest $\mu_{\max }$ (respective means of 0.26 day ${ }^{1}, 0.41$ day ${ }^{1}$, and 0.50 day ${ }^{1}$ ), and the intermediate taxa are the non N-fixing cyanobacteria, small eukaryotes, coccolithophores, and miscellaneous haptophytes (Fig. 2). The differences between taxa in $\mu_{\max }$ are strongly correlated with differences between taxa in $\alpha$ (Fig. 4). The difference between coastal and oceanic isolates is a factor of 1.35, corresponding to means of 0.71 vs. 0.53 (assuming 12-h daylength and $\left.20^{\circ} \mathrm{C}\right)$.

\section{Trait correlations}

The traits $\alpha, I_{\mathrm{opt}}$, and $\mu_{\max }$ exhibit significant correlation structure (Fig. 5). $\alpha$ and $I_{\text {opt }}$ are negatively correlated $(r$

$\left.0.41, p<10^{3}\right), \alpha$ and $\mu_{\max }$ are positively correlated $(r$ $\left.0.59, p<10^{3}\right)$, and $I_{\mathrm{opt}}$ and $\mu_{\max }$ are positively correlated $(r$

$0.18, p \quad 0.01)$. To better discern the possible causes of these correlations, we also used partial correlations to quantify the residual correlation between two traits, once any effect of cell volume and temperature has been accounted for. However, the partial correlations were similar to the raw
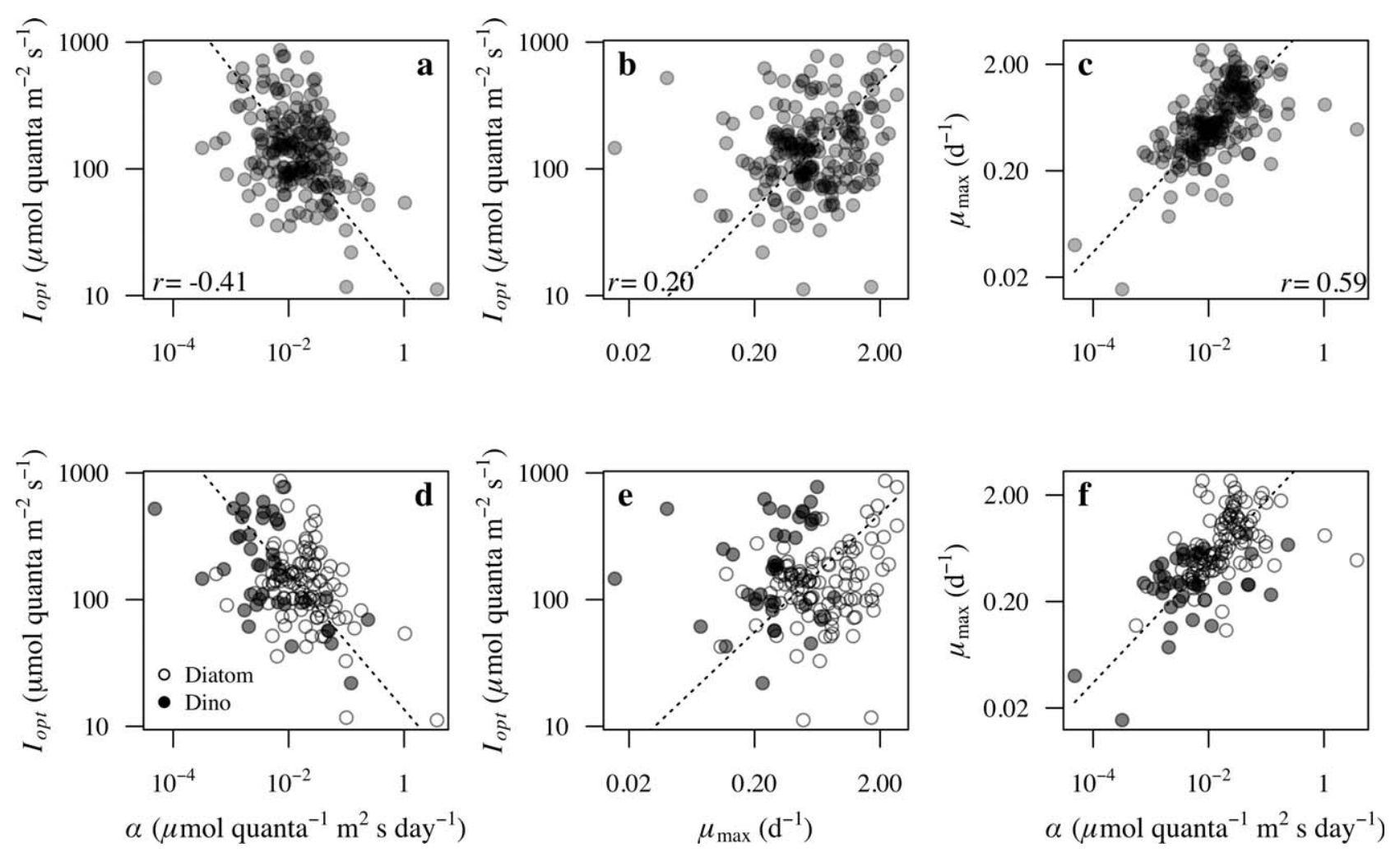

Fig. 5. Trait correlations. (A) $I_{\text {opt }}$ vs. $\alpha$ (B) $I_{\text {opt }}$ vs. $\mu_{\max }$ (C) $\mu_{\max }$ vs. $\alpha$ (D F) show the same correlations with only diatoms and dinoflagellates shown. Dotted lines are the SMA regression fits. Pearson correlation for each pair is shown in (A and $B)$. 


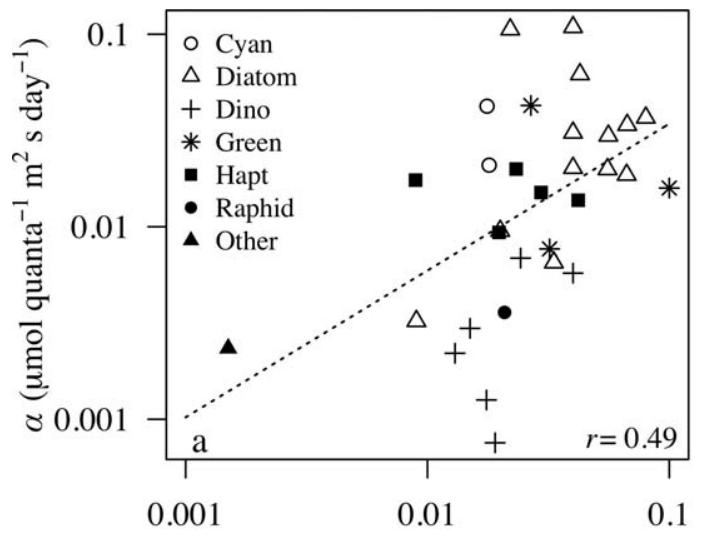

Chl- $a: \mathrm{C}\left(\mathrm{g} \mathrm{g}^{-1}\right)$

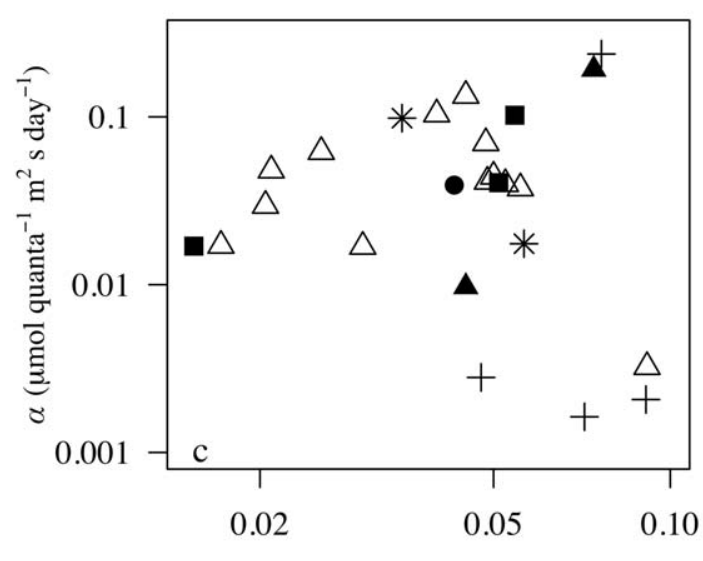

$\mathrm{N}: \mathrm{C}$ (molar)

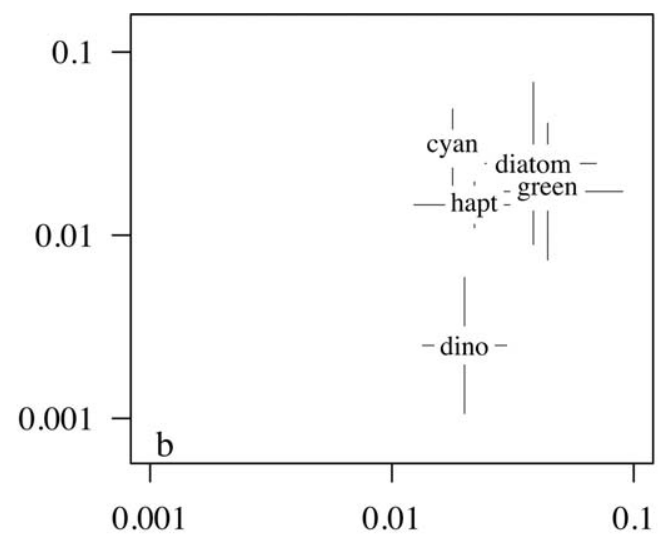

Chl- $a: \mathrm{C}\left(\mathrm{g} \mathrm{g}^{-1}\right)$

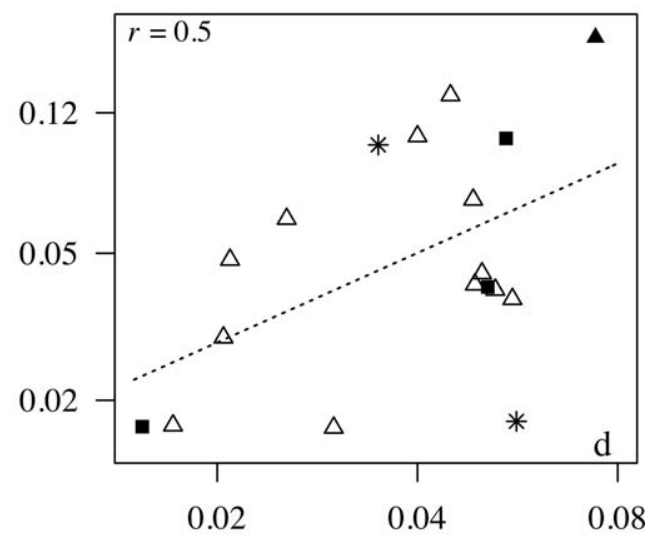

$\mathrm{N}: \mathrm{C}$ (molar)

Fig. 6. Correlation between $\alpha$ and biochemical composition. (A) $\alpha$ vs. Chl $a: \mathrm{C}$. Chl $a: \mathrm{C}$ was measured at the lowest irradiance in the experiment and is presented on a per mass basis. (B) Taxon means \pm standard deviation for $\alpha$ and Chl $a: C$. (C) $\alpha$ vs. $N: C$ measured under strong nitrogen limi tation. Symbols are the same as in (A). (D) $\alpha$ vs. N : C, with dinoflagellates, raphidophytes, Aureoumbra lagunensis, and $P$. multiseries removed.

correlations: $\alpha$ vs. $I_{\mathrm{opt}}, r \quad 0.43, p<10^{-3} ; \alpha$ vs. $\mu_{\max }, r$ $0.57, p<10^{3} ; I_{\text {opt }}$ vs. $\left.\mu_{\max }, r \quad 0.17, p \quad 0.02\right)$. Similar correlation patterns are also seen when looking within the diatoms or dinoflagellates (the two most well-represented taxa; Fig. 5D F), indicating that these trait correlations are not driven primarily by taxonomic differences.

A number of experiments measured chlorophyll content as a function of irradiance, and we used this to test whether $\alpha$ can be predicted from the ratio of chlorophyll to carbon content (Chl $a: \mathrm{C}$ ), measured at the lowest irradiance in the experiment. These two variables were positively correlated (Fig. 6A; Table 1; $r \quad 0.47, p \quad 0.01$, df 26). Taxonomic differences in accessory pigment content may be one cause of taxonomic differences in $\alpha$ (Langdon 1988), but with the limited data available there is no strong evidence for this (Fig. 6B).

We compared $\alpha$ to $\mathrm{N}$ : C for the same species, measured under strong nitrogen limitation, to test for a nitrogen cost of fast growth under low light. When comparing all species for which data is available, no clear patterns emerge (Fig. 6C), but it is noteworthy that the species with both high $\mathrm{N}$ : $\mathrm{C}$ and high $\alpha$ tend to be either harmful dinoflagellates, raphidophytes, or other harmful species such as Aureoumbra lagunensis and Pseudo-nitzschia multiseries. When these two species as well as dinoflagellates and raphidophytes are removed from the analysis, a significant correlation between $\alpha$ and $\mathrm{N}: \mathrm{C}$ emerges (Fig. 6D; $r \quad 0.50, p \quad 0.03$ ).

\section{Discussion}

The traits that define growth as a function of irradiance vary enormously across phytoplankton, with growth efficiency under low light $(\alpha)$ varying over more than three orders of magnitude, optimal irradiance for growth $\left(I_{\mathrm{opt}}\right)$ varying from $\sim 20 \mu \mathrm{mol}$ photons $\mathrm{m}^{2} \mathrm{~s}^{1}$ to $1000 \mu \mathrm{mol}$ photons $\mathrm{m}^{2} \mathrm{~s}^{1}$, and maximum growth rate $\left(\mu_{\max }\right)$ ranging from 0.1 day ${ }^{1}$ to 3.8 day ${ }^{1}$. To better understand the origins and ramifications of this variation, we quantified how 
these traits covary with cell volume and each other, and how they vary across major taxonomic groups and environmental gradients.

\section{Allometric scaling}

$\alpha$ tends to decline with increasing cell size, indicating that larger cells tend to perform poorly under low light, relative to smaller cells (Fig. 1). However, there is large scatter in this relationship, suggesting that cell size is not a strong constraint on how phytoplankton interacts with light. The exponent defining the allometric relationship is poorly constrained, due to the fact that LS slopes are biased to be too shallow by measurement error in cell volume, and SMA slopes are biased to be too steep due to both measurement error and large unexplained natural variation in the traits (Smith 2009). We also found that $\alpha$ tends to increase with temperature. A more thorough discussion of temperature effects will be included in forthcoming work on the interactive effects of light and temperature on phytoplankton growth.

Although the exact slope of the relationship is uncertain, the decline in $\alpha$ with cell size is consistent with theoretical predictions based on the packaging of pigments inside cells. As cell size increases, the same concentration of pigment will absorb less light due to self-shading of pigment molecules (Kirk 1994). Because larger cells suffer an increased package effect, a cost-benefit model predicts that larger cells should invest less in chlorophyll under low light, with the optimal chlorophyll concentration inversely proportional to cell diameter (Finkel et al. 2004). This leads to the prediction that whole-cell photosynthetic rate under strong light limitation should increase with cell volume to the power of $2 / 3$ (Finkel et al. 2004). If the carbon : volume ratio does not change with cell size, and if maintenance respiration is negligible, then the light-limited growth rate should decline with increasing cell volume to the power of $1 / 3$. Carbon : volume in phytoplankton typically scales with cell volume to a power of 0.80 .9 (Menden-Deuer and Lessard 2000), which would lower the predicted scaling exponent for growth rate to something between 0.13 and 0.23. Our results for the allometric scaling of $\alpha$ lie between 0.10 and

0.43 (Table 1), which bracket the range of values that are consistent with theory.

We found no significant relationship between $I_{\text {opt }}$ and cell size. There is evidence that increased self-shading reduces photoinactivation of photosynthesis in larger cells (Key et al. 2010), which might be expected to increase $I_{\text {opt }}$. However, the value of $I_{\mathrm{opt}}$ likely depends on many additional processes, and the tendency for larger cells to have reduced chlorophyll concentration (Finkel et al. 2004) will tend to reduce self-shading.

\section{Taxonomy and environment}

Our analysis of differences between taxonomic groups and between coastal vs. oceanic species revealed a number of intriguing patterns. In short, $\alpha$ differs between taxa, between environments, and also shows an interaction between taxonomy and environment; $I_{\text {opt }}$ differs between environments but not taxa; and $\mu_{\max }$ differs between taxa and between environments with no interaction (Fig. 3). The differences between taxa in $\alpha$ and $\mu_{\max }$ are correlated, such that some groups grow faster than others regardless of irradiance (Fig. 4). The general patterns are consistent with prior analyses (Richardson et al. 1983, Tang 1996, Edwards et al. 2012), and conform to the idea that community structure is to a large extent organized along an axis of turbulent nutrient supply (Margalef 1978, Kudela 2010). The fastest growers are those groups (diatoms and Phaeocystis) that often dominate in turbulent waters; the intermediate groups (coccolithophores, cyanobacteria, small eukaryotes) tend to prosper under more stratified conditions; and the slowest growers (dinoflagellates, raphidophytes, diazotrophs) are also associated with stratified conditions while additionally possessing alternative nutritional strategies. Growth rate under phototrophic conditions may be reduced by the costs of maintaining mixotrophic abilities (Raven 1997), which is common in dinoflagellates (Stoecker 1999) as well as raphidophytes (Jeong 2011). Similarly, growth rates of diazotrophs may be reduced by various energetic costs associated with nitrogen fixation (Großkopf and LaRoche 2012).

For taxa other than diatoms, $\alpha$ tends to be higher and $I_{\mathrm{opt}}$ tends to be lower for oceanic isolates (Fig. 3). This suggests that the oceanic isolates are adapted to lower light availability than coastal isolates. This pattern may be counterintuitive, due to the greater clarity of oceanic waters and the prevalence of strong stratification in the subtropical and tropical regions from which most of the oceanic strains were isolated (Fig. 2). However, stratified waters often exhibit vertical structure in phytoplankton abundance and composition (Furuya and Marumo 1983, Venrick 1999), and there is evidence that many eukaryotic taxa are more abundant at depths closer to the nutricline (Veldhuis and Kraay 2004, Landry et al. 2008). Furthermore, many of the coastal strains were isolated from estuarine and nearshore environments that are shallow and may result in high irradiance experienced by phytoplankton. Oceanic isolates also tend to have lower $\mu_{\max }$ than coastal isolates (Fig. 3), which may be due to higher nutrient supply in coastal environments selecting for rapid growth at the expense of other functions such as efficient nutrient uptake and low nutrient demand (Carpenter and Guillard 1971, Klausmeier et al. 2004, Strzepek and Harrison 2004).

It is interesting that the diatoms, which are by far the most well-represented group in this compilation, differ from the other taxa in having lower $\alpha$ in oceanic isolates and no clear trend for $I_{\mathrm{opt}}$. This may be related to the predominance of diatoms under turbulent conditions in coastal waters (Margalef 1978), but in general these results point to the need for further detailed work on trait distributions across 
environmental gradients. It is also noteworthy that $I_{\mathrm{opt}}$ does not show significant variation across taxa, despite varying between coastal and oceanic isolates. Because most of the taxonomic groups we discuss are widespread in the ocean, it may be the case that coarse taxonomic structure in response to irradiance is relatively weak while closely related genotypes that occupy different light environments can show strong differences (Moore and Chisholm 1999, Rodriguez et al. 2005). In other words, evolutionary constraints to changing light utilization traits in response to selection may be weak. Similarly, varying community trait structure in the English Channel is associated with substantial variation just among the diatoms in response to light and nitrate (Edwards et al. 2013b).

\section{Trait correlations}

The correlation structure among $\alpha, I_{\mathrm{opt}}$, and $\mu_{\max }$ exhibits relatively strong and somewhat complex patterns. $\alpha$ and $I_{\mathrm{opt}}$ are negatively correlated while the other two pairs of traits are positively correlated (Fig. 4). Furthermore, these patterns do not appear to be driven by underlying variation in cell size or temperature conditions, nor by taxonomic trait differences. One way to make sense of this is to posit a general ecological strategy of rapid growth, with some species tending to grow faster at all irradiances, resulting in higher values for all three traits. This axis of variation is consistent with trait differences between taxa (Fig. 4). Rapid growth may come at the cost of other traits unrelated to growthirradiance relationships, such as resistance to predation or nutrient use efficiency. A related hypothesis is that prospering under relatively turbulent, deeply mixed conditions selects for increased $\alpha$ and also increased $\mu_{\max }$, because populations are mixed across depths of high and low light, making both of these traits important for competitive ability (Huisman and Weissing 1994). These are also conditions where nutrient supply is relatively high, which may mean that investment in the nitrogen-rich machinery of light capture, carbon fixation, and protein synthesis (Klausmeier et al. 2004, Talmy et al. 2013) is affordable.

The negative correlation between $\alpha$ and $I_{\text {opt }}$ adds some complexity to this picture. It is possible that these traits are negatively correlated simply because a high growth efficiency (high $\alpha$ ) allows a species to reach $\mu_{\max }$ at a lower irradiance, which could push the peak of the curve toward the left (Fig. 1A). Alternatively, high $\alpha$ may come at a cost of greater sensitivity to photoinhibition, which would also reduce $I_{\text {opt }}$. Fully understanding the patterns of trait correlation in this analysis will likely require studies of a greater number of traits, because the allocation of energy and resources among many functions can permit some traits (e.g., $\alpha$ and $\mu_{\max }$ ) to be positively correlated when other, unmeasured traits suffer the cost (Edwards et al. 2013a). In general, the correlation patterns are similar to those found in an analysis of trait variation across freshwater species
(Schwaderer 2011). The authors found a negative correlation between $\alpha$ and $I_{\mathrm{opt}}$, a positive correlation between $\alpha$ and $\mu_{\text {max }}$, and no correlation between $I_{\text {opt }}$ and $\mu_{\max }$. Although we found a positive correlation between $I_{\mathrm{opt}}$ and $\mu_{\max }$ here, it is the weakest of the three correlations.

The relationship between Chl- $a$ : C and $\alpha$ is consistent with the expectation that greater investment in pigments will increase growth efficiency under low light (Falkowski et al. 1985, Langdon 1988). Nonetheless this relationship is noisy, which may be due to the fact that Chl- $a$ : C does not account for the role of other pigments (Langdon 1988), as well as maintenance respiration rates that vary across species. It is possible that taxonomic differences in $\alpha$ are driven by taxonomic differences in chlorophyll investment, but with the limited data there is not a strong relationship between mean taxon $\alpha$ and Chl- $a$ : C (Fig. 6B). Alternatively, taxa may vary in the effective optical absorption cross section per Chl-a, but the data compiled in Langdon (1988) does not show any differences between taxa (analysis not shown).

Investment in the pigment-protein complexes that harvest light increases under low irradiance (Dubinsky and Stambler 2009), and these components can comprise a large proportion of cellular nitrogen (Geider and LaRoche 2002). However, species are not infinitely plastic, and there are large differences between species in Chl $a$ : C even under saturating irradiance (Dubinsky and Stambler 2009). We tested whether species that have a high $\alpha$ also have a high nitrogen investment $(\mathrm{N}$ : C) when nitrogen is the only factor limiting growth. The patterns observed (Fig. 6C,D) are consistent with this idea, although dinoflagellates and species known to be harmful bloomers break the pattern by having a low $\alpha$ despite their high $\mathrm{N}$ requirements. This may be due to $\mathrm{N}$ allocation to other functions, such as mixotrophy (Raven 1997) or toxins that contain $\mathrm{N}$ (Van de Waal et al. 2014). For the other species in the dataset, the possession of high $\alpha$ appears to come at a cost of increased $\mathrm{N}$ demand under N-limiting conditions, which should reduce competitive ability under $\mathrm{N}$ limitation and could potentially lead to a trade-off between light and nutrient $(\mathrm{N})$ competitive abilities. These data also highlight a mechanistic link between the light-dependent growth of phytoplankton and nutrient biogeochemistry (Klausmeier et al. 2004). It is also likely that variation in $\mathrm{N}: \mathrm{C}$ across species reflects variation in $\mathrm{C}$ accumulation under excess irradiance and nutrient limitation (Shifrin and Chisholm 1981).

We have taken advantage of the large number of published growth-irradiance experiments to investigate how traits related to light utilization vary across species and environments. To fully understand many of the resulting patterns will require further investigation, such as detailed comparisons of community trait structure across environmental conditions, and a better physiological understanding of the constraints and tradeoffs that affect trait variation (Talmy et al. 2013, Polimene et al. 2014). In addition, many aspects of light ecophysiology have not been considered in our analysis, such as responses to 
fluctuating light (Litchman 2000, Key et al. 2010), including the dynamics of physiological acclimation, and variation in the spectral quality of light (Wood 1985, Stomp et al. 2004). Ultimately, a synoptic view of multiple key phytoplankton traits across many species will be essential for characterizing the processes that structure phytoplankton communities.

\section{References}

Alvain, S., C. Moulin, Y. Dandonneau, and H. Loisel. 2008. Seasonal distribution and succession of dominant phytoplankton groups in the global ocean: a satellite view. Global Biogeochem. Cycles 22: 1 15. doi:10.1029/ 2007GB003154

Bates, D., M. Maechler, and B. Bolker. 2012. lme4: linear mixed-effects models using S4 classes. R package version 0.999999-0. Available from http://cran.r-project.org/web/ packages/lme4/index.html.

Boyd, P. W., R. Strzepek, F. Fu, and D. A. Hutchins. 2010. Environmental control of open-ocean phytoplankton groups: now and in the future. Limnol. Oceanogr. 55: 1353 1376. doi:10.4319/1o.2010.55.3.1353

Brand, L. E., and R. R. L. Guillard. 1981. The effects of continuous light and light intensity on the reproduction rates of 22 species of marine phytoplankton. J Exp Mar Biol Ecol 50: 119 132. doi:10.1016/0022-0981(81)900459

Carpenter, E. J., and R. R. L. Guillard. 1971. Intraspecific differences in nitrate half-saturation constants for three species of marine phytoplankton. Ecology 52: 183 185. doi: $10.2307 / 1934753$

Cullen, J. J., and J. G. Macintyre. 1998. Behavior, physiology, and the niche of depth-regulating phytoplankton, p. 559 580 In D. M. Anderson, A. D. Cembella, and G. M. Hallegraeff [eds.], Physiological ecology of harmful algal blooms. NATO ASI Series. Springer-Verlag.

Dubinsky, Z., and N. Stambler. 2009. Photoacclimation processes in phytoplankton: mechanisms, consequences, and applications. Aquat. Microb. Ecol. 56: 163 176. doi: 10.3354/ame01345

Edwards, K. F., C. A. Klausmeier, and E. Litchman. 2013a. A three-way trade-off maintains functional variation under variable resource supply. Am. Nat. 182: 786 800. doi: $10.1086 / 673532$

Edwards, K. F., E. Litchman, and C. A. Klausmeier. 2013b. Functional traits explain phytoplankton community structure and seasonal dynamics in a marine ecosystem. Ecol. Lett. 16: 56 63. doi:10.1111/ele.12012

Edwards, K. F., M. K. Thomas, C. A. Klausmeier, and E. Litchman. 2012. Allometric scaling and taxonomic variation in nutrient utilization traits and maximum growth rate of phytoplankton. Limnol. Oceanogr. 57: 554566. doi:10.4319/1o.2012.57.2.0554

Eilers, P. H. C., and J. C. H. Peeters. 1988. A model for the relationship between light intensity and the rate of pho- tosynthesis in phytoplankton. Ecol. Modell. 42: 199215. doi:10.1016/0304-3800(88)90057-9

Falkowski, P., Z. Dubinsky, and K. Wyman. 1985. Growthirradiance relationships in phytoplankton. Limnol. Oceanogr. 30: 311 321. doi:10.4319/lo.1985.30.2.0311

Finkel, Z. V. 2001. Light absorption and size scaling of lightlimited metabolism in marine diatoms. Limnol. Oceanogr. 46: 86 94. doi:10.4319/lo.2001.46.1.0086

Finkel, Z. V., A. J. Irwin, and O. Schofield. 2004. Resource limitation alters the $3 / 4$ size scaling of metabolic rates in phytoplankton. Mar. Ecol. Prog. Ser. 273: 269 279. doi: 10.3354/meps273269

Follows, M. J., S. Dutkiewicz, S. Grant, and S. W. Chisholm. 2007. Emergent biogeography of microbial communities in a model ocean. Science 315: 1843 1846. doi:10.1126/ science. 1138544

Furuya, K., and R. Marumo. 1983. The strucure of the phytoplankton community in the subsurface chlorophyll maxima in the western north Pacific ocean. J Plankton Res. 5: 393 406. doi:10.1093/plankt/5.3.393

Geider, R. J., and B. A. Osborne. 1989. Respiration and microalgal growth: a review of the quantitative relationship between dark respiration and growth. New Phytol. 112: 327 341. doi:10.1111/j.1469-8137.1989.tb00321.x

Geider, R. J., T. Platt, and J. A. Raven. 1986. Size dependence of growth and photosynthesis in diatoms: a synthesis. Mar. Ecol. Prog. Ser. 30: 93 104. doi:10.3354/ meps030093

Geider R., and J. La Roche. 2002. Redfield revisited: variability of C:N:P in micro algae and its biochemical basis. European Journal of Phycology 37: 117.

Gerla, D. J, Mooij, W. M and J. Huisman. 2011. Photoinhibition and the assembly of light-limited phytoplankton communities. Oikos 120: 359368.

Gelman, A., and Hill, J. 2006. Data analysis using regression and multilevel/hierarchical models. Cambridge Univ. Press.

Großkopf, T., and J. LaRoche. 2012. Direct and indirect costs of dinitrogen fixation in Crocosphaera watsonii WH8501 and possible implications for the nitrogen cycle. Front. Microbiol. 3: 1 10. doi:10.3389/fmicb.2012.00236

Hickman, A. E., Dutkiewicz, S., Williams, R. G., and M. J. Follows. 2010. Modelling the effects of chromatic adaptation on phytoplankton community structure in the oligotrophic ocean. Marine Ecology Progress Series 406: 117.

Hood, R. R., and others. 2006. Pelagic functional group modeling: progress, challenges and prospects. Deep-Sea Res. II 53: 459 512. doi:10.1016/j.dsr2.2006.01.025

Huisman, J., and F. J. Weissing. 1994. Light-limited growth and competition for light in well-mixed aquatic environments: an elementary model. Ecology 75: 507520.

Hurvich, C. M., and C.-L. Tsai 1989. Regression and time series model selection in small samples. Biometrika 76: 297 307. doi:10.1093/biomet/76.2.297 
Jeong, H. J. 2011. Mixotrophy in red tide algae raphidophytes. Journal of Eukaryotic Microbiology 58: 215222.

Key, T., A. McCarthy, D. A. Campbell, C. Six, S. Roy, and Z. V. Finkel. 2010. Cell size trade-offs govern light exploitation strategies in marine phytoplankton. Environ. Microbiol. 12: 95 104. doi:10.1111/j.1462-2920.2009.02046.x

Kirk, J. T. O. 1994. Light and photosynthesis in aquatic ecosystems, 2nd ed. Cambridge Univ. Press.

Klausmeier, C. A., E. Litchman, T. Daufresne, and S. A. Levin. 2004. Optimal N:P stoichiometry of phytoplankton. Nature 429: 171 174. doi:10.1038/nature02454

Kudela, R. M. 2010. Does horizontal mixing explain phytoplankton dynamics? Proc. Natl. Acad. Sci. USA 107: 18235 18236. doi:10.1073/pnas.1013175107

Kuznetsova, A., P. B. Brockhoff, and R. H. B. Christensen. 2013. lmerTest: tests for random and fixed effects for linear mixed effect models (lmer objects of lme4 package). $\mathrm{R}$ package version 1.2-0. Available from http://cran.r-project.org/web/packages/lmerTest/index.html.

Landry, M. R., S. L. Brown, Y. M. Rii, K. E. Selph, B. R. Bidigare, E. J. Yang, and M. P. Simmons 2008. Depthstratified phytoplankton dynamics in Cyclone Opal, a subtropical mesoscale eddy. Deep-Sea Res. II 55: 1348 1359. doi:10.1016/j.dsr2.2008.02.001

Langdon, C. 1988. On the causes of interspecific differences in the growth irradiance relationship for phytoplankton. 2. A general review. J. Plankton Res. 10: 1291 1312. doi: 10.1093/plankt/10.6.1291

Lavaud, J., R. F. Strzepek, and P. G. Kroth. 2007. Photoprotection capacity differs among diatoms: possible consequences on the spatial distribution of diatoms related to fluctuations in the underwater light climate. Limnol. Oceanogr. 52: 1188 1194. doi:10.4319/lo.2007.52.3.1188

Litchman, E. 1998. Population and community responses of phytoplankton to fluctuating light. Oecologia 117: 247 257. doi:10.1007/s004420050655

Litchman, E. 2000. Growth rates of phytoplankton under fluctuating light. Freshw. Biol. 44: 223 235. doi:10.1046/ j.1365-2427.2000.00559.x

Litchman, E., and C. A. Klausmeier. 2001. Competition of phytoplankton under fluctuating light. American Naturalist 157: 170 187. doi:10.1086/318628

Litchman, E., and C. A. Klausmeier. 2008. Trait-based community ecology of phytoplankton. Annu. Rev. Ecol. Evol. Syst. 39: 615 639. doi:10.1146/annurev.ecolsys.39.110707.173549

Marañon, E., and others. 2013. Unimodal size scaling of phytoplankton growth and the size dependence of nutrient uptake and use. Ecol. Lett. 16: 371 379. doi:10.1111/ ele. 12052

Margalef, R. 1978. Life-forms of phytoplankton as survival alternatives in an unstable environment. Oceanolog. Acta 1: 493509 .

Menden-Deuer, S., and E. J. Lessard. 2000. Carbon to volume relationships for dinoflagellates, diatoms, and other pro- tist plankton. Limnol. Oceanogr. 45: 569 579. doi: 10.4319/1o.2000.45.3.0569

Moore, L. R., and S. W. Chisholm. 1999. Photophysiology of the marine cyanobacterium Prochlorococcus: ecotypic differences among cultures isolates. Limnol. Oceanogr. 44: 628 638. doi:10.4319/1o.1999.44.3.0628

Passarge, J., Hol S., Escher M., and J. Huisman. 2006. Competition for nutrients and light: stable coexistence, alternative stable states, or competitive exclusion? Ecological Monographs 76: 57 72.

Platt, T., Gallegos C. L., Harrison W. G. 1980. Photoinhibition of photosynthesis in natural assemblages of marine phytoplankton. Journal of Marine Research 38: 103111.

Polimene, L., C. Brunet, M. Butenschön, V. MartinezVicente, C. Widdicombe, R. Torres, and J. I. Allen. 2014. Modelling a light-driven phytoplankton succession. J Plankton Res. 36: 214 229. doi:10.1093/plankt/fbt086

Polimene, L., C. Brunet, M. Butenschön, V. MartinezVicente, C. Widdicombe, R. Torres, and J. I. Allen. 2014. Modelling a light-driven phytoplankton succession. J Plankton Res. 36: 214 229. doi:10.1093/plankt/fbt086

Raven, J. A. 1997. Phagotrophy in phototrophs. Limnol. Oceanogr. 42: 198 205. doi:10.4319/lo.1997.42.1.0198

Richardson, K., J. Beardall, and J. A. Raven. 1983. Adaptation of unicellular algae to irradiance: an analysis of strategies. New Phytol. 93: 157 191. doi:10.1111/j.14698137.1983.tb03422.x

Rodriguez, F., E. Derelle, L. Guillou, F. Le Gall, D. Vaulot, and H. Moreau. 2005. Ecotype diversity in the marine picoeukaryote Ostreococcus (Chlorophyta, Prasinophyceae). Environ. Microbiol. 7: 853 859. doi:10.1111/j-14622920.2005.00758.x

Schwaderer, A. S., K. Yoshiyama, P. T. Pinto, N. G. Swenson, C. A. Klausmeier, and E. Litchman. 2011. Eco-evolutionary differences in light utilization traits and distributions of freshwater phytoplankton. Limnol. Oceanogr. 56: 589 598. doi:10.4319/lo.2011.56.2.0589

Shifrin, N. S., and Chisholm, S. W. 1981. Phytoplankton lipids: interspecific differences and effects of nitrate, silicate and light-dark cycles. J. Phycol. 17: 374 384. doi:10.1111/ j.1529-8817.1981.tb00865.x

Six, C., Z. V. Finkel, A. J. Irwin, and D. A. Campbell. 2007. Light variability illuminates niche-partitioning among marine picocyanobacteria. Plos One 12: e1341. doi: 10.1371/journal.pone.0001341

Smith, R. J. 2009. On the use and misuse of the reduced major axis for line-fitting. Am. J. Phys. Anthropol. 140: 476 486. doi:10.1002/ajpa.21090

Stoecker, D. K. 1999. Mixotrophy among Dinoflagellates. J. Eukaryotic Microbiol. 46: 397 401. doi:10.1111/j.15507408.1999.tb04619.x

Stomp, M., and others. 2004. Adaptive divergence in pigment composition promotes phytoplankton biodiversity. Nature 432: 104 107. doi:10.1038/nature03044 
Stomp, M., J. Huisman, L. Vörös, F. R. Pick, M. Laamanen, T. Haverkamp, and L. J. Stal. 2007. Colorful coexistence of red and green picocyanobacteria in lakes and seas. Ecol. Lett. 10: 290 298. doi:10.1111/j.1461-0248.2007. 01026.X

Strzepek, R. F., and P. J. Harrison. 2004. Photosynthetic architecture differs in coastal and oceanic diatoms. Nature 431: 689 692. doi:10.1038/nature02954

Talmy, D., J. Blackford, N. J. Hardman-Mountford, A. J. Dumbrell, and R. J. Geider. 2013. An optimality model of photoadaptation in contrasting aquatic light regimes. Limnol. Oceanogr. 58: 1802 1818. doi:10.4319/ lo.2013.58.5.1802

Tang, E. P. Y. 1996. Why do dinoflagellates have lower growth rates? J. Phycol. 32: 80 84. doi:10.1111/j.00223646.1996.00080.x

Van de Waal, D. B., Smith, V. H., Declerck, S. A. J., Stam E. C. M., and J. J. Elser. 2014. Stoichiometric regulation of phytoplankton toxins. Ecol. Lett. 17: 736 742. doi: 10.1111/ele.12280

Veldhuis, M. J. W., and G. W. Kraay. 2004. Phytoplankton in the subtropical Atlantic Ocean: towards a better assessment of biomass and composition. Deep-Sea Res. I 51: 507 530. doi:10.1016/j.dsr.2003.12.002

Venrick, E. L. 1999. Phytoplankton species structure in the central North Pacific, 1973-1996: variability and persistence. J. Plankton Res. 21: 1029 1042. doi:10.1093/plankt/ 21.6.1029
Warton, D. I., Duursma, R. A., Falster, D. S., and S. Taskinen. 2012. smatr 3 an R package for estimation and inference about allometric lines. Methods Ecol. Evol. 3: 257259. doi:10.1111/j.2041-210X.2011.00153.X

Warton, D. I., I. J. Wright, D. S. Falster, and M. Westoby. 2006. Bivariate line-fitting methods for allometry. Biol. Rev. 81: 259 291. doi:10.1017/S1464793106007007

Wood, A. M. 1985. Adaptation of photosynthetic apparatus of marine ultraphytoplankton to natural light fields. Nature 316: 253 255. doi:10.1038/316253a0

Wood, S. 2012. gamm4: Generalized additive mixed models using mgcv and lme4. R package version 0.1-6. Available from http://cran.r-project.org/web/packages/gamm4/index. html.

Yoshiyama, K., Mellard, J. P., Litchman, E., and C. A. Klausmeier. 2009. Phytoplankton competition for nutrients and light in a stratified water column. American Naturalist 174: 190203.

\section{Acknowledgment}

This work was supported by National Science Foundation grants DEB 0845825 to CK, DEB 0845932 to EL, OCE 0928819 to EL and CAK, DEB 1136710 to EL and CAK.

Submitted 4 June 2014 Revised 13 November 2014 Accepted 27 November 2014 Associate editor: Heidi M. Sosik 